\title{
De objeto a sujeito: uma contribuição feminista à história e à filosofia
}

\author{
Izilda Cristina Johanson' (iD) 0000-0002-6648-5552 \\ 'Universidade Federal de São Paulo, Guarulhos, SP, Brasil. 07252-312
}

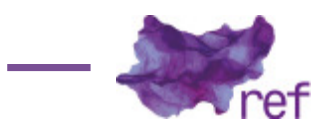

\begin{abstract}
Resumo: Trata-se de apresentar um estudo de caso, tomado na filosofia existencialista, por meio do qual a abordagem da questão da relação entre mulher e filosofia explicita duas questões de grande relevância. Em primeiro lugar, a da pretensa universalidade do sistema conceitual cunhado pelo filósofo que, sob o crivo da existência concreta, revela uma realidade consideravelmente seletiva e parcial que, muitas vezes, em lugar de combater, reforça certos lugares comuns da opinião e pré-juízos sobre as diferenças e opressões de gênero. Em segundo, e em contrapartida, a do interesse aparentemente localizado na situação da mulher, que leva a filósofa a abrir e em alguma medida libertar o campo das investigações filosóficas, no sentido da realização de sua integração à vida humana. Este é um dos passos fundamentais dado na direção da constituição da mulher como sujeito autêntico, também do conhecimento.
\end{abstract}

Palovras-chave: mulher; filosofia; feminismo; existencialismo; sujeito.

From Object to Subject: A Feminist Contribution to History and to Philosophy

Abstract: It is intended to present a case study, taken from the existentialist philosophy, which the women and philosophy relationship approach depicts two great relevant questions. Firstly, the alleged universality of conceptual system coined by the phylosopher that, upon the scrutiny of concrete existence, discloses a somewhat selective and partial reality that, oftenly, rather than combating, reinforces certain commonplace opinions and prejudices about the differences and gender oppression. Secondly, on the other hand, the interest apparently located in the status of the women, that drives the female phylosopher to open and, to some extent, unleash the philosophical field of the investigations, towards the achievement of their connection to human life. That is one of the key steps taken toward the constitution of women as an authentic subject, and of knowledge as well.

Keywords: Woman; Philosophy; Feminism; Existentialism; Subject.

Ser feminista é também um modo de integrar o ser filósofa. Pois, há séculos, uma feminista é uma mulher que não delega a ninguém o cuidado de pensar em seu lugar (Michèle LE DOEUFF, 1989).

\section{Colocação do problema (mulher e filosofia)}

A questão do lugar e do papel da mulher na filosofia é indissociável da discussão acerca do lugar e do papel da mulher na vida em meio à sociedade humana. A filosofia - quer queira, quer não - não se constitui numa realidade à parte, numa ilha rodeada de senso comum por todos os lados, num mundo isolado, ideal e muito menos perfeito. Em todo caso, a partir dela, se apresentam estudos, reflexões, discussões que visam mostrar, no mais das vezes, como, por exemplo, os filósofos são seres excepcionais, como que, tomada a devida distância da ação e da vida comum, eles são capazes de pensar e pensam coisas extraordinárias nunca antes pensadas e, com isso, frequentemente lançam luz às questões e aos problemas da realidade empírica para as quais, sem eles, nunca se conceberiam soluções.

Minha proposta de abordagem parte de um lugar um pouco diferente deste. O que pretendo apresentar e pôr em discussão diz respeito, é certo, à relação entre filosofia e vida social, entre filosofia e mundo historicamente constituído, mas em meio à qual o que se constata é, antes, a reiteração e mesmo a legitimação, por parte da primeira, de certos males relativos ao segundo. 
Indo diretamente ao ponto. O problema que me abriu os olhos para essa relação nada heroica nem gloriosa entre a filosofia e a vida vivida empiricamente foi a questão do lugar e do papel da mulher no mundo e na filosofia: tanto na vida como na filosofia, o lugar e o papel da mulher costumam ser geralmente os mesmos; ela é frequentemente alijada da ação e do pensamento criador, da produção de conhecimento e, num mesmo movimento, reduzida a um corpo, a um corpo sexuado, basicamente. Partamos do princípio.

Tanto na vida como na filosofia, foram (têm sido) hegemonicamente os homens que têm dito e ainda dizem o que a humanidade, as coisas, o conhecimento, a vida e, portanto, as mulheres também, são. Eles não precisam definir nem dizer o que o indivíduo do sexo masculino é, dado que ser homem costuma ser também sinônimo de ser humanidade e que, por conseguinte, os homens definem o ser do seu sexo definindo o próprio ser da humanidade. A definição da mulher - ser distinto, diferente, estranho e difícil de compreender? -, basicamente alguém que, por princípio, e porque contrário ao homem que se reconhece como tal, é corpo e não pensamento, que é carne e não ideia, que é sexo e não conhecimento, ao contrário, precisa receber uma definição, uma descrição, uma explicação à parte. Nisto temos que reconhecer que a filosofia se iguala ao mais baixo e simplório pensamento comum - ou será, talvez, que o produz e o legitima? -, em todo caso, com a diferença em relação a este último de ter a seu favor, geralmente, um sistema conceitual muito bem arquitetado e quase sempre irrefutável para se sustentar racionalmente, discursivamente, cientificamente, objetivamente.

Mas eis que a mulher resolve tomar a palavra para dizer não apenas a si mesma, mas para dizer também, a partir disso, algo da maior relevância sobre essa pretensa humanidade, sobre esse pretenso sujeito universal e ontológico do filósofo e, com isso, algo também acerca da sistematicidade, do alcance e da medida do conhecimento que ele produz.

Possível reação imediata da assim constituída legitimidade filosófica: não é filosofia o que ela faz. Ora, por quê? Hipótese: porque tudo o que a filosofia dela não pode fazer é o que, em princípio, se esperaria que fizesse, a saber, reiterar teoricamente, conceitualmente, metodologicamente, qualquer um desses sistemas filosóficos que, se não inventam, ao menos dão lugar de peso à opressão à qual ela está sujeita. Pois bem, vindo de um filho do próprio sistema - seja esse filho fiel ou infiel, ou ingrato, revolucionário ou reformista, não importa -, vindo de um filho do sistema, os parricídios, as rupturas, negações, descontinuidades costumam ser não apenas aceitáveis como necessárias e desejáveis; ao menos em algum momento da história o serão, se não no presente próprio, no futuro histórico certamente. O mesmo não poderia se dar com alguém que, afinal de contas, não costuma ser considerada habitante da filosofia, que em relação a esta é frequentemente considerada estrangeira e, por isso também, uma voz ilegítima. Ou então, não sendo de todo estrangeira, tem nela algum lugar, um lugar muito peculiar, a saber, pois, neste caso, é imprescindível precisar: o de objeto, muito mais raramente o de um sujeito do conhecimento. Eis aqui nossa questão.

Na introdução de O segundo sexo, Simone de Beauvoir (2016) expõe essa questão de que, em termos de experiência vivida e também de conhecimento, a mulher não tem sido senão aquilo que o homem decide que ela seja. Ela cita Le Rapport d'Uriel, de Benda: "O homem pensa a si sem a mulher; ela não, sem o homem" (BEAUVOIR, 2016, p. 12). Esse é um tema recorrente nas discussões de filósofas feministas, sobretudo a partir do século XX. E a questão diz respeito a esse lugar relativo da mulher (ser inessencial, inautêntico, o segundo sexo, o outro sexo, o ser relativo) e às suas implicações: no âmbito do pensamento filosófico, inclusive. Pois se essa declaração de Benda citada por Beauvoir é válida, ela o é, no entender de algumas pensadoras com as quais me coloco de acordo, apenas superficialmente. No sentido de que, de fato, é possível constatar que um homem fala de si próprio quando dirige sua investigação à humanidade de modo geral e faz isso igualando homem, indivíduo do sexo masculino, à humanidade, ao que considera ser o sujeito em geral, ou universal, e, neste sentido, absoluto (seja em termos de uma universalidade abstrata ou, o contrário, no de um conjunto de indivíduos homens concretos, históricos etc.; em todo caso, trata-se de homens e tão somente homens); no entanto - e é para isto que as filósofas feministas costumam chamar a atenção, a começar pela própria Beauvoir -, se um homem pensa a si, melhor dizendo, se ele pensa sua humanidade de homem, ele o faz muitas vezes opondo a existência feminina à sua, edificando a si mesmo por contraste: em geral, contrastando ao seu ser ativo, livre, criador, a existência de uma passividade, de uma incapacidade feminina e de uma sexualidade que reduz esse ser outro unicamente ao seu corpo útil. A título de ilustração, poderíamos retomar aqui a síntese já tão revisitada e glosada, a respeito da mulher definida como ser de "cabelos longos e ideias curtas" (ver LE DOEUFF, 1980). ' Esse mote (cuja autoria nunca foi comprovada e que, no entanto, não deixa de ser

\footnotetext{
' Esse é um epíteto feminino, pode-se dizer já clássico. É também o título de um ensaio, também clássico, de Michèle Le Doeuff, filósofa feminista, pensadora de referência especialmente para a questão da relação entre mulher e filosofia e, a partir dela, a discussão acerca do método do "ponto de vista" nas construções conceituais e filosóficas. A lista de aberrações ditas e escritas sobre as mulheres pode ser bem grande e não é o caso aqui de a passarmos em revista. Mas faço uma menção também especial a Les femmes de Platon à Derrida ou l'impossible sujet d'histoire, de Françoise Collin, Evelyne Pisier e Eleni Varikas (COLLIN, Françoise; PISIER, Évelyne; VARIKAS, Eleni. Les Femmes de Platon à Derrida - Anthologie critique. Paris: Plon, 2000). Nele, o que mais instiga é a questão de fundo que não se responde
} 
significativo ter sido popularmente atribuída ao autor de O mundo como vontade... e representação) dá uma boa medida do que interessa destacar, a saber: esse expediente tão comum na história do pensamento e de seus protagonistas de "pensar o humano ativo e livre como masculino graças a um jogo complexo de diferenciações, de afirmações, de dominações e de redução da mulher a uma unidimensionalidade sexual" (LE DOEUFF, 1989, p. 104). Ou seja, de "determinar o humano positivo por contraste e graças à produção de uma imagem denominada mulher" (LE DOEUFF, 1989, p. 104).

Pois bem, é algo acerca dessa imagem que aqui nos levará de $O$ segundo sexo a O ser e o nada, e vice-versa: na obra de Jean-Paul Sartre (1997), as poucas vezes em que se faz referência ao sexo feminino, a imagem constituída é aquela de um ser que ora é anexado ao mundo da conquista, ora é figura negativa ou ameaçadora. Quanto à Beauvoir - e não é evidente que seja assim, eis a questão - tudo se passa de modo muito diferente. Se Beauvoir alcança de verdade o problema da opressão do sexo feminino com vistas aos caminhos possíveis para sua libertação, isto se deve não apenas ao fato de ela, Simone de Beauvoir, ser mulher e, como tal, ter as condições mais elementares e fundamentais - o tão significativo e justamente reivindicado lugar de fala para abordar um problema relacionado a uma experiência que nenhum homem, por mais boa vontade que tenha, jamais poderá experimentar por si mesmo; isto se deve, antes de tudo e principalmente, ao fato de que, enquanto mulher de pensamento, enquanto filósofa, Beauvoir faz escolhas teóricas e metodológicas muito próprias, e muito diferentes também das de seu companheiro intelectual e de vida, as quais, no entanto, não são indiferentes à perspectiva à qual ela se coloca em meio à filosofia e ao mesmo tempo no mundo.

Os conceitos de má-fé em Sartre e em Beauvoir se prestarão a explicitar isso que interessa apresentar aqui. Em princípio, eles parecem ter saído da mesma fonte, mas, colocados face a face, nos mostram também a que lugares distintos e opostos podem nos levar os empreendimentos de um e de outra, fundamentalmente, em virtude de suas respectivas escolhas de pontos de vista teórico, metodológico, ou seja, de projeto de conhecimento. Mais que isto, no caso de Beauvoir particularmente - e isso é o que mais fundamentalmente interessa, mais do que apenas reiterar aquilo que já se reconhece há um bom tempo, isto é, que o que ela escreve é filosofia, tão legítima e original como qualquer outra do seu tempo e que nada deve, em termos de rigor teórico às demais -, seu projeto, que é fundamentalmente ético, poderá nos dizer também qual tipo de exigência pode e mesmo precisa ser feita ao conhecimento em geral, e à filosofia em particular, para que certas existências - como a de uma mulher, por exemplo - possam, enfim, ocupar lugar de sujeito autêntico nos tantos mundos possíveis e desejáveis de habitar, incluindo, sem dúvida, o da filosofia.

\section{Má-fé e opressão (o ponto de vista de O segundo sexo)}

A abordagem da má-fé, em Beauvoir, tem seu ponto de partida no entendimento acerca do modo como esta autora empreende seu projeto, essencialmente ético, em consonância à referência fundamental - alegada e defendida já nas primeiras páginas de O segundo sexo - da moral existencialista. Segundo a moral existencialista, a condição humana é definida pela ambiguidade. Para pensá-la nos seus aspectos mais singulares e específicos, se lançará mão de um quadro em meio ao qual as noções se apresentarão sempre em duplas. É assim que, ao longo da obra dos existencialistas, nos encontraremos com polaridades como: imanência/transcendência; em-si/parasi; autêntico/inautêntico; assunção/má-fé; indivíduo/mundo. Como ressalta Beauvoir (1947), assumir nossa fundamental ambiguidade é assumir que "é no conhecimento das condições autênticas de nossa vida que precisamos apoiar a força de viver e as razões para agir" (p. 14). Em outras palavras, é assumir-se em meio à vida como indivíduo: em meio à vida concreta, histórica, material, como indivíduo concreto, histórico, em relação, em situação, ou seja, como sujeito.

A primeira coisa a destacar dessa discussão é que, para Beauvoir, o indivíduo é sujeito não sob qualquer condição, mas quando se afirma como tal, isto é, quando assume sua liberdade e sua transcendência em meio ao mundo; o que significa dizer que o indivíduo é sujeito na autenticidade. É esta, a autenticidade, que liga os termos subjetividade e liberdade: a liberdade, ressalta nossa autora, "é a fonte de onde surgem todas as significações e todos os valores; ela é a condição original de toda justificação da existência" (BEAUVOIR, 1947, p. 31). De sorte que, quando o indivíduo se afirma como sujeito, ele assume sua liberdade e sua transcendência diante do mundo: querer-se sujeito, querer-se moral e querer-se livre, completa Beauvoir (1947, p. 32), são uma só e mesma coisa.

Contudo, "ao lado da pretensão de todo indivíduo de se afirmar como sujeito, que é uma pretensão ética, ressalta nossa autora, há também a tentação de fugir de sua liberdade e de se

inteiramente, ou não cessa tão facilmente de ser respondida, sobre como leríamos esses pensadores todos (que relegam a mulher ao lugar de outro absoluto, seja via idealização romântica da musa inspiradora, seja por meio da mais pura brutalidade pensante mesmo) se os valores expostos em suas obras - em particular, relacionados ao ser mulher - fossem explicitamente colocados no ponto de partida de nossas análises sobre eles. Essa não me parece uma pergunta banal, ao menos não se encarada sem má-fé. 
constituir em coisa" (BEAUVOIR, 2016, p. 17-18); pois, se não é possível não ser livre, dado que a liberdade é constitutiva do ser humano, é possível, contudo - e justamente porque há liberdade -, querer não ser livre; é possível, pois, a um indivíduo, negar a própria liberdade. "É um caminho nefasto esse, porque passivo, alienado, perdido [...] Mas é um caminho fácil: evitam-se com ele a angústia e a tensão da existência autenticamente assumida" (BEAUVOIR, 2016, p. 18). Haverá, de todo modo, neste caso, degradação do para-si em em-si, da liberdade em facticidade, do sujeito em objeto, do sujeito autêntico em inautêntico, logo, má-fé.

A partir deste ponto é que a discussão moral existencialista começa a ser encaminhada na direção do projeto mais propriamente beauvoiriano, pois que aqui se chega ao ponto de partida para O segundo sexo.

A tese fundamental deste livro, como o próprio título indica, se sustenta em duas constatações. A primeira é que os indivíduos são sexuados. A segunda, que o indivíduo do sexo feminino é o segundo sexo. Ser segundo significa, neste caso, que o sexo feminino, o sexo da mulher, é o outro sexo, aquele que se constitui sempre em relação ao primeiro, ao Um, que é o sexo masculino. Aparentemente, nada poderia haver de excepcional nisso, afinal, é na relação de alteridade que o sujeito se constitui fundamentalmente, e a própria Beauvoir (2016) diz isso: "o sujeito só se põe em se opondo; ele pretende afirmar-se como essencial e fazer do outro o inessencial, o objeto" (p. 14). A questão toda está em que, se a mulher é o indivíduo do outro sexo para o homem, o contrário não acontece, a recíproca não é verdadeira. Esta é a tese fundamental sobre a qual se ergue $O$ segundo sexo. Dizendo sem rodeios, a mulher é o outro sexo para o homem - e, neste caso, a relação de alteridade está completa, é autêntica -, mas o outro sexo, para a mulher, não é o do homem; para um indivíduo do segundo sexo, o outro sexo não é o masculino, mas o feminino, ou seja, o seu mesmo. A mulher é o outro para si mesma. Ela não é o outro do Outro, ela é o outro do Um. Não há, neste caso, uma relação de alteridade pura, autêntica. Na relação entre o masculino e o feminino, um dos dois termos, destaca Beauvoir, a saber, o primeiro, se impõe como único e essencial. ${ }^{2}$ Deste modo, toda a relatividade concernida ao seu correlativo é negada: a mulher é, assim, lançada à condição de outro absoluto.

Toda mulher é, de saída, constituída como ser inessencial; dominada, ela acaba se submetendo a um ponto de vista estrangeiro sobre si mesma. Mas este só pode ser a partir da opressão. O indivíduo do segundo sexo é, pois, aquele que se constitui em função e como produto de uma situação, ou melhor, de um conjunto de situações de opressão: numa palavra, é um sujeito inautêntico.

Está dado o fio condutor que nos guiará pelos dois volumes de O segundo sexo, o livro:

Como se entende que entre os sexos essa reciprocidade não tenha sido colocada, que um dos termos se tenha imposto como o único essencial, negando toda relatividade em relação ao seu correlativo, definindo este como alteridade pura? Por que as mulheres não contestam a soberania do macho? Nenhum sujeito se define imediata e espontaneamente como inessencial: não é o Outro que, se definindo como Outro, define o Um. Mas para que o outro não se transforme no Um é preciso que se sujeite a esse ponto de vista alheio. De onde vem essa submissão da mulher? (BEAUVOIR, 2016, p. 14).

Para pavimentar esse solo de respostas possíveis, no primeiro volume Beauvoir vai se encarregar de mostrar, em primeiro lugar, que o segundo sexo não é natural, não é causado, nem determinado: nem biologicamente, nem psiquicamente, nem materialmente. O segundo sexo não é destino, mas, fundamentalmente, resultado de escolhas e de projetos humanos. Como estes se realizam concretamente como existência? Isto será o assunto do segundo volume, no qual Beauvoir descreverá situações concretas em meio às quais a criança, a menina, a jovem, a mulher se tornam, enfim, segundo sexo. Apenas no final do segundo volume a questão da má-fé retorna, então, não mais como teoria pura, nos moldes de Por uma moral da ambiguidade, mas em meio a perspectivas concretas, pois que serão descritas as situações em meio às quais se constituem alguns casos exemplares de segundo sexo de má-fé. ${ }^{3}$

Se, como visto ao longo de todo o livro, as situações de homens e mulheres são profundamente diferentes e que, confrontando tais situações, se constata que

as deles Ihes dão muito mais possibilidades concretas de projetar sua liberdade no mundo e que, portanto, confrontar o uso que em seus limites os homens e as mulheres fazem de sua

\footnotetext{
${ }^{2}$ Não percamos de vista, é o homem que se coloca como sinônimo e equivalente de ser humano, que se coloca no centro e no alto daquilo que muito comumente e inespecificamente chama de humanidade. É fato que, de 1949 , quando $O$ segundo sexo foi publicado, para cá, muita coisa no terreno das relações de gênero mudou, no entanto, mesmo em meio a tantas importantes conquistas no sentido de uma vida mais igualitária em termos sexuais e de gênero, mesmo assim, não há como negar que essa constatação permanece ainda bastante atual.

${ }^{3}$ São três figuras principais desse segundo sexo de má-fé que Beauvoir descreve. Elas não esgotam, evidentemente, a questão, mas, ao mesmo tempo que elucidam uma situação singular, não deixam também de constituírem exemplos ou modelos a partir dos quais diferentes variações podem vir a se configurar. Essas existências de má-fé, pode-se dizer modelares, ligadas ao sexo feminino e descritas em O segundo sexo são, como se sabe, a da narcísica, a da amorosa e a da mística, todas objetos do último capítulo da obra.
} 
liberdade é, a priori, uma tentativa desprovida de sentido, posto que eles a empregam mais livremente (BEAUVOIR, 2016, p. 438).

Também é preciso considerar, ressalta nossa autora, que "a liberdade se encontra inteira em cada um, homens e mulheres e que, neste sentido, sob diversas formas as armadilhas da máfé, as mistificações da seriedade ameaçam-nos tanto uns como outros" (BEAUVOIR, 2016, p. 439). Contudo, com essa ressalva, que não é nada irrelevante, de que essa liberdade, na mulher, permanece predominantemente abstrata e vazia.

Assim sendo, e tal como se passa em relação aos que não têm a possibilidade de construir o que quer que seja, cumpre-lhe recusar os limites de sua situação e procurar abrir os caminhos para si no futuro. A revolta é, então, o principal - se não o único - caminho para isso. A "resignação, por sua vez, e ao contrário, não passa de uma renúncia, de uma fuga: não há, para a mulher, outra saída senão a de trabalhar pela sua libertação" (BEAUVOIR, 2016, p. 439). Isto significa dizer também que essa libertação só poderá ser coletiva, dado que ela exige a mudança das condições sociais, materiais, econômicas, culturais da condição feminina. Dito de modo inverso, essa libertação nunca poderá advir de uma luta solitária, de mulheres isoladas. Um esforço no sentido dessa espécie de individualismo autossuficiente, será, enfim, um esforço de má-fé:

Houve e ainda há numerosas mulheres [ressalta Beauvoir] que buscam solitariamente realizar sua salvação individual, que tentam justificar sua existência no seio de sua imanência, isto é, realizar a transcendência na imanência. Trata-se do último esforço, por vezes ridículo, às vezes patético, da mulher encarcerada para converter sua prisão em um céu de glória, e sua servidão em liberdade soberana (BEAUVOIR, 2016, p. 439).

Em resumo, em Beauvoir, a questão da autenticidade e de seu oposto correlato, a má-fé, não pode se constituir desvinculadamente do problema da opressão. Para esta autora, não obstante o produto de ambas, no indivíduo, seja o mesmo, a saber, a inautenticidade, não pode haver má-fé onde há opressão. A má-fé, que leva à falta moral, pressupõe a liberdade e, para Beauvoir, uma liberdade concreta. Ora, numa situação de opressão tudo o que há de concreto são apenas os obstáculos à liberdade, e isto é o que a transforma numa pura abstração. É para este ponto preciso que dirijo a célebre e tão citada passagem de $A$ força da idade, em que Beauvoir (2009) menciona a divergência dela em relação a Sartre:

Eu sustentava que, do ponto de vista da liberdade tal qual Sartre a definia - não resignação estoica e, sim, superação ativa do dado -, as situações não são equivalentes: qual a superação possível para uma mulher encerrada no harém? Mesmo essa clausura, há diferentes maneiras de vivê-la, dizia-me Sartre. Obstinei-me durante muito tempo e só cedi superficialmente. No fundo, eu tinha razão. Mas, para defender minha posição, fora preciso abandonar o terreno da moral individualista, logo idealista, em que nos colocávamos (p. 339).

\section{Má-fé e sistema (o ponto de vista de O ser e o nada)}

O ponto de partida para abordar não propriamente o conceito de má-fé sartreano, pois que não é este o objeto deste ensaio, mas algo acerca da nossa questão sobre certo imaginário filosófico relacionado ao lugar e ao papel da mulher implicado nele, será, precisamente, esse citado acima: o terreno do idealismo, que, segundo a filósofa, é preciso abandonar de uma vez por todas.

No projeto filosófico sartreano não há nenhuma teoria sobre feminino ou sobre a diferença entre os sexos. Insisto que o propósito aqui não é o de censurar Sartre, nem nenhuma filosofia em particular por isso, pois o que interessa-e é por essa via que pretendo entrar em O ser e o nada-, é destacar justamente o contrário, ou seja, os momentos em que este filósofo faz referência à mulher, ao indivíduo do sexo feminino, não obstante este não seja precisamente seu objeto de investigação. Esses momentos não são muitos, mas são muito específicos. E vêm atender a demandas mais específicas ainda.

A primeira referência à mulher se dá no capítulo dedicado justamente à má-fé. São duas mulheres descritas ali: a mulher frígida e aquela que recusa as investidas de seu pretendente num encontro. Nos demais capítulos a figura da mulher retorna várias vezes, e sempre de modo exclusivamente associado à imagem de um corpo objeto de desejo masculino. Le Doeuff, de quem acompanho a argumentação, reconhece que esse expediente de Sartre está longe de ser original; ele o liga, na verdade, a uma antiga tradição, que remonta à antiguidade pelo menos. ${ }^{4}$ Contudo, Sartre não deixa de atualizá-la, isto é, de dar a esse recurso um sentido mais propriamente

\footnotetext{
${ }^{4}$ O próprio título do livro de Michèle Le Doeuff, L'Étude et le rouet, faz referência direta ao objeto de escolha de Hipárquia de Maroneia (c. 325 a.C.), filósofa cínica, única mulher mencionada no compêndio de Diógenes de Laércio. O episódio que este autor narra acerca dessa filósofa trata de uma disputa entre Hipárquia e Teôdoro, na qual ela lhe refuta e este lhe responde não com argumentos, mas the arrancando a roupa e expondo o seu corpo: de mulher. Hipárquia não se abala com tal atitude e, diante do questionamento subsequente de Teôdoro a respeito da pertinência da presença dela entre pensadores (homens), rebate com a célebre indagação: "acreditas que tomei uma decisão errada se dediquei à minha educação o tempo que teria dedicado ao tear?".
} 
existencialista. É assim que, em L'Étude et le rouet, Le Doeuff lança mão de uma categoria do próprio sistema sartreano para caracterizar esse procedimento de reduzir a mulher ao objeto do desejo masculino: o "solipsismo de fato". Esse conceito, como todo leitor e toda leitora de Sartre conhece, descreve a posição de um sujeito nas situações em que as outras pessoas são reduzidas à função delas para ele. Trata-se de uma atitude basicamente de indiferença, de uma "cegueira em relação aos outros". É assim, por exemplo, que o bilheteiro não é outra coisa senão aquele que recolhe os bilhetes e o garçom do café não é senão a função de servir os consumidores, diz Sartre (1999, p. 473) em O ser e o nada. Da mesma maneira, pode-se dizer que "as mulheres descritas nos exemplos fenomenológicos não são senão a função de provocar o desejo de um eventual amante, mas com esta precisão: ela sempre decepciona esse interesse, esquivando-se dele de maneira desonesta" (LE DOEUFF, 1989, p. 76).

Eis os exemplos que relacionam mulher e má-fé. Primeiro o da mulher frígida, caracterizado como caso de má-fé patológica. O segundo, uma má-fé normal, o da mulher num primeiro encontro amoroso que recusa o desejo que, entende-se, o desejo de seu pretendente provocou nela, enganando-se a si mesma e deixando também, com isso, o vazio da conquista frustrada no coração da existência de seu possível amante. No primeiro caso, dado tratar-se de uma patologia, Sartre recorre aos trabalhos de Stekel, psiquiatra vienense, para corroborar sua tese. ${ }^{5}$

Pois bem, quem é a mulher de má-fé (frígida) de O ser e o nada? Basicamente, uma mulher que, conforme o relato de seu marido ao médico, dá "indícios objetivos" de sentir desejo e, ao mesmo tempo, o recusa sexualmente. E o que determina ser essa uma atitude de má-fé? Ao que tudo indica, o juízo de um terceiro. Mas não de um terceiro qualquer. Uma espécie de argumento de autoridade aqui se faz presente. Quem efetivamente detecta e confirma ao médico que há sinais objetivos de desejo na mulher? A considerar o que diz Sartre, o marido dela. Cito textualmente a passagem em que ele diz isso:

Note-se, em primeiro lugar, que não se trata de dissimular complexos profundamente soterrados em trevas semifisiológicas, mas condutas objetivamente verificáveis que elas não podem deixar de constatar quando as realizam: frequentemente, de fato, o marido revela a Stekel que sua mulher deu sinais objetivos de prazer, os quais a mulher, interrogada, empenha-se veemente em negar. Trata-se de atividade de alheamento (SARTRE, 1999, p. 100).

Subindo (ou descendo) na escala da autoridade masculina, quem autoriza Sartre a trazer esse caso para ilustrar a má-fé patológica que ele visa opor ao psiquismo labiríntico do inconsciente psicanalítico? O Dr. Stekel. Eis que o ciclo se fecha: da autoridade do marido, retomada pela do psiquiatra, Sartre retoma a sua mesma para constituir seu parecer em relação à mulher: ela é de má-fé. E para dar esse diagnóstico, não foi preciso maiores investigações, ainda que aparentemente se possa estar pisando em terreno científico, dado que ele cita um trabalho de medicina. A expressão de Sartre que expõe sucintamente essa perspectiva é essa: "sinais objetivos de prazer". Isto parece resolver, para ele, a questão do rigor e da objetividade exigida a qualquer pensamento que se queira consequente e válido. Mas, então, não estamos falando de signos e sinais? Estes exigem de fato a participação de um terceiro que os interprete ou traduza para um segundo? Neste caso, os signos são interpretados e ao mesmo tempo objetivos? É o que parece, pelo menos quando o discurso e o diálogo - acerca do indivíduo do sexo feminino - se fazem entre indivíduos do sexo masculino. Façamos, pois, como propõe Le Doeuff, modifiquemos os personagens dessa mesma cena incorporada por Sartre e invertamos os status sociais deles:

Pensemos então num homem que vai à psiquiatra porque, nas relações sexuais sente não prazer, mas desprazer e desespero; a mulher dele revela à psiquiatra que, no entanto, ele, seu marido, dá sinais objetivos de prazer... Quem poderia erguer um conceito tão importante e fundamental como o de má-fé sobre algo assim? Que tipo de leitor pode dar crédito a isto? (LE DOEUFF, 1989, p. 86). ${ }^{6}$

Alguns protestos nos poderiam ser dirigidos aqui: este é um único exemplo, diriam, não podemos condenar o conceito como um todo por causa de um único exemplo. De fato, como se diz desde o início, o propósito aqui não é o de condenar nada nem ninguém. Contudo, é preciso repetir, esse não é um exemplo isolado: em O ser e o nada, todas as situações em que a mulher é realmente questão, ou seja, sujeito, ela o é nessa condição de sujeito inautêntico, para retomarmos os termos fenomenológicos existencialistas, na definição do próprio Sartre (1999): "alguém que é o que é à maneira do 'não ser o que é', ou não é o que é 'à maneira do ser o que é'” (SARTRE, 1999, p. 113). Ela, a mulher na fenomenologia sartreana, a mulher-objeto do conhecimento do filósofo,

\footnotetext{
${ }^{5}$ Simone de Beauvoir também recorre ao mesmo livro de Sketel em muitos momentos de O segundo sexo, mas, é preciso dizer desde já, de uma maneira completamente diferente. Lá, trata-se sempre, e afinal, de uma descrição do estado e de uma narrativa em relação a uma situação, como a descrita frigidez, por exemplo. O recurso possui sempre um valor especulativo, visa descrever e perscrutar a possível frigidez, entre outras situações. Este não é o caso de Sartre. ${ }^{6}$ Nos tempos atuais, poderíamos considerar que toda uma discussão, por exemplo, sobre consentimento, nas quais muitas feministas se empenham com dedicação, teria aqui um bom ponto de partida e um terreno certamente fértil a explorar.
} 
é um indivíduo de má-fé, ela não corresponde às expectativas desejantes daquele que fala, que detém o discurso, do autoconstituído sujeito autêntico: do desejo, do conhecimento, e do desejo de conhecimento também.

O segundo exemplo, o do encontro amoroso de um casal, repete, por outros caminhos não muito diferentes deste primeiro, o mesmo tipo de entendimento. Mais uma vez, segundo Sartre, é a recusa da mulher de assumir o desejo que sente (pelo homem que a deseja) que fundamenta seu argumento em favor da má-fé. E o que esse exemplo nos diz? Em primeiro lugar, que não é possível que essa mulher, que consentiu nesse primeiro encontro com um homem que se supõe estar interessado nela, não tenha consciência das verdadeiras intenções dele. Na verdade, segundo o autor, ela não só tem consciência das intenções do seu pretendente - que são certamente mobilizadas pelo "sentimento dirigido por inteiro à pessoa dela", ou seja, à sua "liberdade plena", mas também, e ao mesmo tempo, pelo "desejo todo inteiro dirigido ao seu corpo como objeto" (SARTRE, 1997, p. 101) - como é preciso que ela o tenha para, justamente, poder recusá-lo. Isto é o que parece autorizar Sartre a afirmar que, desta vez - ou seja, diferente do caso anterior da mulher frígida, que dissimula para si própria o seu próprio desejo sexual -, essa mulher "que sabe perfeitamente das intenções que o homem que lhe fala tem a seu respeito" é de má-fé, na medida em que "se nega a captar o desejo como ele é" (SARTRE, 1997, p. 101): ela retém na conduta do seu par apenas o que nela tem de respeito, admiração e estima, realizando, desse modo, o "divórcio entre corpo e alma" (SARTRE, 1997, p. 102 [grifos nossos]). Evidentemente, não se trata aqui de contestar o caráter carnal do desejo que ele, o amante, assim como grande parte das pessoas em toda parte sente ou pode sentir umas pelas outras; não pretendemos de modo algum revestir o presente ensaio com nenhum tipo de discurso moralista ou moralizante. A questão que interessa é seguramente de outra ordem. E para irmos diretamente a ela, retomarei o tema da objetividade, então tomada como critério de legitimidade (ou não) dos pareceres e diagnósticos que nos são oferecidos nesse capítulo de $O$ ser e o nada dedicado às condutas de má-fé. Sigamos, portanto, com Sartre na passagem em que ele apresenta o caso dessa mulher que vai num primeiro encontro, que sabe perfeitamente das intenções do homem que lhe fala e que, cedo ou tarde, terá de tomar uma decisão em relação a isso, mas que "não quer sentir a urgência disso, atendo-se apenas ao que de respeitoso e discreto oferece a atitude do companheiro":

(ela) Não apreende como tentativa de estabelecer os chamados 'primeiros contatos', ou seja, não quer ver as possibilidades de desenvolvimento temporal apresentadas por essa conduta: limita-se ao que é no presente, só quer interpretar nas frases que ouve o seu sentido explícito, e se lhe dizem 'eu te amo muito', despoja a frase de seu âmago sexual: vincula aos discursos e à conduta de seu interlocutor significações imediatas, que encara como qualidades objetivas (SARTRE, 1997, p. 101 [grifos nossos]).

Vemos aqui um caso particular em que certas percepções são reduzidas a interpretações que permitem, por sua vez, que certo indivíduo - a mulher do casal, no caso - fuja de uma situação que, segundo nosso filósofo, ela não quer ver se concretizar, ao menos não naquele momento. Esse exemplo pode ser ainda mais ilustrativo se contrastado com o primeiro, da mulher frígida. Neste, como vimos, Sartre nos apresenta uma mulher que diz sentir desprazer com o sexo com seu marido, e o próprio, que constata que, apesar do que diz, ela "dá sinais objetivos de prazer". Nesse segundo exemplo, nosso filósofo descreve um primeiro encontro entre dois enamorados e se concentra em expor aquilo que a mulher não constata, nem verifica, mas interpreta no discurso e na conduta de seu pretendente: segundo nosso filósofo, ela atribui a estes "significações imediatas que encara como qualidades objetivas" (grifos nossos). Pois bem, no primeiro caso, o objeto e a objetividade ligam-se à figura feminina (a mulher e o desejo dessa mulher são esse objeto) e é essa objetividade que autoriza o sujeito homem (o marido, em primeiro lugar, seguido do médico e do filósofo) a dar seu parecer e constituir seu discurso acerca dela. No segundo caso, é o inverso que acontece, o objeto e a objetividade ligam-se, então, à figura e ao desejo masculino (as intenções e comportamento do pretendente é que seriam esses objetos), mas agora será justamente isso, essa objetividade, que irá desautorizar o sujeito mulher a constituir seu discurso, ou entendimento, a respeito do indivíduo homem. No primeiro caso, não se trata de interpretação de um sujeito, mas de reconhecimento por parte deste de sinais objetivos (da mulher); no segundo, ao contrário, estamos diante de uma interpretação de frases e de comportamentos subjetivos (do homem). Ou seja, a objetividade e a subjetividade passam a ter valores e funções completamente opostas e díspares, conforme o caso, conforme o sujeito, conforme o objeto em questão. Quando o sujeito é do sexo masculino (marido, médico, filósofo) e a mulher (seu) objeto, não há interpretação, mas verificação, constatação de algo objetivo; ele é o sujeito e ela é exclusivamente objeto para esse sujeito. No entanto, quando, ao contrário, o sexo feminino deve ocupar o lugar de sujeito (a enamorada diante de seu pretendente) e o homem de (seu) objeto, a legitimidade da objetividade cai por terra, melhor dizendo, o objeto é logo retransformado em sujeito e é isso, no mais, que permite que as ações e atitudes dele possam ou não corresponder àquilo que a mulher "interpreta" ou diz ser. Mais precisamente, é essa inversão imediata de objeto em sujeito, e vice-versa, por parte do filósofo, que o autoriza a afirmar, por fim, 
algo do tipo "ela não viu tudo", "não viu o todo", ou, como de fato o afirmou, ela não viu "o desejo como ele é".

Por fim, em comparação com O segundo sexo, pode-se dizer, e para ficarmos no mais essencial, que se a definição conceitual de má-fé em Sartre e Beauvoir é praticamente a mesma, o modo como cada um deles constrói concretamente esse conceito é completamente diferente. Em ambos a má-fé culmina no sujeito inautêntico, com a diferença de que, em Beauvoir, a contradição na mulher consiste no mascaramento de sua servidão, na transformação de sua opressão em uma situação vantajosa e consentida: nunca numa não correspondência em relação à expectativa desejante de um amante, real ou possível, ou do marido, ou sujeito Um que for.

\section{Imaginário filosófico e existencialismo (um ponto de vista feminista)}

É chegado o momento de retomarmos o ponto central da questão acerca do lugar e do papel da mulher em cada uma das obras mencionadas - respectivamente, O Segundo sexo e $O$ ser e o nada. Da análise do conceito de má-fé chega-se ao entendimento de que, em Sartre, e de modo totalmente oposto ao que se passa em Beauvoir, a mulher que habita sua obra remete, antes de tudo, a uma imagem, produto de um imaginário: não simplesmente aquele de seu autor, mas, para empregarmos o conceito de Le Doeuff, o de um imaginário filosófico, o qual Sartre atualiza e, deste modo, reitera. Ainda que a concepção de um imaginário de cunho psicológico, ou mesmo mítico (por exemplo, a hipótese de um masculino genérico, ou arcaico, cultural de todo modo, inscrito ocultamente, ou inconscientemente na obra em questão) não precise ser necessariamente descartada, assim como a perspectiva idiossincrática do próprio autor e de seu tempo, o que se põe em questão aqui resulta de um ponto de vista diferente destes. Diz respeito, pois, ao entendimento da imagem como fragmento de um imaginário que não é nem propriamente elemento (favorável ou desfavoravelmente) estranho ao saber que o discurso visa constituir, nem também, oposto simétrico, recurso ou expediente (consciente ou inconsciente) do próprio discurso filosófico com vistas a atingir algo como uma sensibilidade (mais primitiva ou essencial talvez) de seu leitor; trata-se, enfim, de um imaginário que possui, por assim dizer, "status filosófico" e do qual, portanto, a obra não pode prescindir; um imaginário que é, neste sentido, solidário do conceito, empreendido pelo sistema e interno a ele (LE DOUEFF, 1980, p. 16-17). ${ }^{7}$ Como tal, esse imaginário filosófico é de natureza ambivalente: torna-se referência tanto de uma contradição interna do pensamento produzido, pois que o aparato conceitual visa produzir não deve ser, por princípio, da ordem do imagético, quanto de seu oposto, ou seja, uma cumplicidade secreta com ele: tornase, enfim, o lugar em que esse sistema, ou construto de pensamento, vem depositar seus inevitáveis impossíveis, e também seus fantasmas, seus limites, numa palavra, o seu Outro.

Tudo leva a crer que Simone de Beauvoir esteve atenta a esse tipo de risco ao qual uma empreitada conceitual, principalmente de caráter sistemático como a de Sartre, pode sucumbir. ${ }^{8}$ Seu empreendimento teórico fez-se no sentido do "abandono desse terreno idealista" - logo, abstrato - essencial à produção, à atualização e à reiteração de certos fantasmas (LE DOEUFF, 1980 , p. 22), ${ }^{9}$ terreno fértil à produção de um imaginário, no qual, no mais, segundo ela, ambos, ela e Sartre, se encontravam no início de seus percursos intelectuais. Isto tudo com vistas a alcançar problemas concretos e, sobretudo, de perspectivas igualmente concretas. Neste sentido, chama atenção certa passagem da Introdução de $O$ segundo sexo na qual a autora põe em xeque o próprio lugar de onde se ergue muito do discurso do filósofo:

\footnotetext{
${ }^{7}$ Trata-se, em suma, de um imaginário entendido então não mais como elemento clandestino, exótico, um intruso que, por isso, necessita ser expurgado de um conhecimento que só pode se constituir legitimamente pela via racional e da abstração conceitual (modelo mais próximo do alvo de uma crítica de tipo bachelardiano, por exemplo); nem tampouco como elemento exterior e comum, um tipo de imaginário mítico, arcaico, cuja finalidade seria fazer, por sua vez, algo como uma ponte entre o conhecimento erudito e letrado do filósofo e a sensibilidade vulgar, o senso comum (versões mais ou menos próximas de um imaginário mitológico, ou mesmo arquetípico, de tipo junguiano, por exemplo): "que a imagem seja radicalmente heterogênea ou completamente isomórfica aos corpos de conceitos que ela traduziria na linguagem do Outro, o estatuto de elemento do trabalho filosófico lhe é recusado - ela não é uma parte da empreitada; nos dois casos, ela é reveladora daquilo que Foucault chama de teratologia de um saber - e daquilo que o bom leitor, aquele que passou pela disciplina filosófica, deve saber passar ao largo" (LE DOUEFF, 1980, p. 16-17). E é a partir dessa constatação e desse entendimento de que a produção de conhecimento implica inevitavelmente na produção de algum imaginário, ou de imaginários possíveis, que Michèle Le Doeuff constrói o conceito de "imaginário filosófico", que se distingue de um imaginário mais especificamente psicológico, ou mítico, em virtude de ser produzido por conceitos, dentro de um campo mais ou menos específico (mas não, evidentemente, isolado) que é o da filosofia, e por ela. ${ }^{8}$ É preciso ressaltar, contudo, que em nenhum momento, até onde se tem notícia, Beauvoir se opõe a Sartre, nem o refuta ou contradiz. Como se sabe, Beauvoir se reconhecia como escritora e não como filósofa. Mais que isto, dizia - como o fez, por exemplo, em suas memórias - que o filósofo de verdade do casal era Sartre e não ela. Entretanto, também nesse ponto de partida negativo se pode ancorar o princípio de originalidade de seu pensamento, afinal, que filosofia está em questão, também para Beauvoir, quando ela própria, Simone de Beauvoir, diz não ser filósofa? 9 "As imagens são esse pelo que toda filosofia dogmatiza de maneira imediata, decreta um 'é assim' contra o qual ninguém pode abrir polêmica, uma vez que é entendido que o bom leitor passa ao largo dessas 'ilustrações' - isto é o que permite, no mais, que as imagens sejam tão ativas. [...] Jogando sobre um cálculo de desprazer, sobre uma repartição de valores afetivos, ela cria ainda uma sedução, ela produz e estrutura um fantasma" (LE DOEUFF, 1980, p. 22).
} 
Agastou-me, por vezes, no curso de conversações abstratas, ouvir os homens dizerem a mim: 'você pensa assim porque é uma mulher'. Eu sabia que minha única defesa era responder: 'penso-o porque é verdadeiro', eliminando assim a minha subjetividade. Não se tratava, em hipótese alguma, de replicar: 'e você pensa o contrário porque é um homem', pois está subentendido que o fato de ser um homem não é uma singularidade (BEAUVOIR, 2016, p. 12).

Contudo, para que o sexismo e o discurso falocrático se transformem numa filosofia de perspectiva feminista, não basta que a discussão apenas passe das mãos de um pensador homem para as de uma pensadora mulher (o "lugar de fala" é, sem dúvida, fundamental e imprescindível à constituição de uma subjetividade autêntica, mas não é, por si só, o suficiente), é preciso também que algumas escolhas no campo ético e teórico sejam feitas. Em relação à Beauvoir, e conforme Le Doeuff, pode-se dizer que a modificação mais manifesta, e sem dúvida fundamental, da problemática existencialista operada por ela é esta: ela adota explicitamente a perspectiva da moral existencialista, visando explorar uma parte da realidade social e intersubjetiva, ao invés de, por exemplo, construir sistemas conceituais.

O que nossa filósofa vai retomar do existencialismo, portanto, não é um conjunto de 'aquisições teóricas' constituídas em dogmática, mas valores: a autenticidade e a liberdade formam o pano de fundo ético de seu trabalho teórico, e isto não é banal (LE DOEUFF, 1989, p. 105).

\section{Considerações finais}

Não são poucas as contribuições de O segundo sexo para a história do século XX, na medida em que a questão das relações entre mulher e ação, mulher e pensamento, pensamento e ação, intrinsecamente presente nessa obra, abre um campo de reflexão baste amplo e diverso, com forte e irreversível impacto na vida prática, privada e pública, de muitas mulheres até hoje. Neste sentido, essa obra é, sem dúvida, uma incitação à libertação. No que diz respeito ao campo filosófico, a contribuição de Beauvoir não é menos significativa. Em sua obra, ela cria e desenvolve o conceito de segundo sexo, o qual, por sua vez, mobiliza de modo extremamente original noções caras à história da filosofia, tais como as de sujeito e de objeto, de Eu e de Outro, de ipseidade e de alteridade, de heteronomia e de autonomia, de inautenticidade e de autenticidade, de servidão e de liberdade, entre outras. Entendo que seja principalmente no ponto de vista, na perspectiva teórica adotada pela autora-essencialmente feminista, pois - que se encontra, fundamentalmente, a originalidade de sua contribuição filosófica.

Não obstante, certos teóricos confortavelmente instalados na filosofia historicamente constituída ${ }^{10}$ poderiam muito bem dirigir considerações acerca dessa alegada importância filosófica da obra de Beauvoir. Poderiam argumentar, por exemplo - e muitos o fazem até hoje -, que O segundo sexo trata de questões importantes, mas muito pontuais e localizadas, na medida em que se dedica, fundamentalmente, a descrever e explicitar elementos significativos relacionados à opressão de gênero, enquanto que a grande filosofia (crítica, sistemática, empirista, racionalista, analítica, todas elas caberiam de algum modo nesse grupo) precisa ter um alcance para muito além de realidades e problemas específicos e pontuais - talvez concretos? E é aí que está o ponto, pois se, por um lado, se poderia argumentar que $O$ segundo sexo é uma obra importante, mas apenas para uma pretensa fenomenologia ou política "das mulheres", e não para um conjunto inespecífico, mais abrangente ou unificado dos indivíduos e seres humanos - o que fomentaria, para a reflexão filosófica, na mais benevolente das hipóteses, uma suposta área ou disciplina específica, algo como uma "filosofia feminina" ou mesmo uma "filosofia feminista" -, podemos, em oposição a esse entendimento, replicar com uma indagação a respeito de que totalidade mais abrangente ou unificada, abstrata ou concreta, de indivíduos e seres humanos exatamente, os filósofos e uma filosofia oficialmente reconhecida como tal, em geral, trataria. Parodiando o célebre e admirável discurso de Sojourner Truth, de meados do século XIX, nos EUA, perguntaríamos, assim, aos supostos guardiões legítimos do rigor filosófico: "e eu, mulher, não sou um indivíduo humano concreto?"."1

\footnotetext{
${ }^{10}$ Refiro-me à filosofia principalmente ensinada hoje nas universidades e instituições de ensino, estudada nos principais programas de pesquisa e pós-graduação no Brasil e no resto do mundo (parece que, nisto, não se encontram muitas diferenças, pelo menos entre os chamados países ocidentais), a filosofia tematizada e oficializada nos planos de ensino dos cursos de formação, a filosofia tematizada nos artigos das revistas acadêmicas, aquela predominantemente presente nas bibliografias desses artigos científicos, aquelas tomadas como temas de congressos, colóquios, encontros de filosofia, cuja promoção e exploração também costumam receber os principais recursos de financiamento de agências de fomento.

11 "Aqueles homens ali dizem que as mulheres precisam de ajuda para subir em carruagens, e devem ser carregadas para atravessar valas, e que merecem o melhor lugar onde quer que estejam. Ninguém jamais me ajudou a subir em carruagens, ou a saltar sobre poças de lama, e nunca me ofereceram melhor lugar algum! E não sou uma mulher? Olhem para mim? Olhem para meus braços! Eu arei e plantei, e juntei a colheita nos celeiros, e homem algum poderia estar à minha frente. E não sou uma mulher? Eu poderia trabalhar tanto e comer tanto quanto qualquer homem - desde que eu tivesse oportunidade para isso - e suportar o açoite também! E não sou uma mulher? Eu pari treze filhos e vi a maioria deles ser vendida para a escravidão, e quando eu clamei com a minha dor de mãe, ninguém a não ser Jesus me ouviu! E não sou uma mulher?" (Tradução: Osmundo Pinho, Universidade Federal do Recôncavo da Bahia, Cachoeira/University of Texas, Austin. A versão mais conhecida foi recolhida pela
} 
De resto, se se entende que o conceito de segundo sexo seja importante e fundamental apenas para o que se passa internamente a um campo supostamente restrito do pensamento e da ação designado por feminismo (seja a versão ou corrente que for dentro do amplo espectro compreendido pelos tantos e diversos feminismos), então será a própria relação da filosofia "não feminista" (ora, mas o que seria ela, uma filosofia sem especificações, absoluta, apenas escrita com letra maiúscula, talvez?) com a ação, com a vida concreta de indivíduos humanos concretos - a práxis humana -, que precisaria ser posta em questão com urgência, ou seja, o próprio sentido da filosofia, de fazer filosofia, que precisará ser posto, então, em relevo. Neste caso, teríamos, pois, de voltar ao velho topos do "por que filosofia?", "por que filósofo?", "o que significa se orientar no pensamento?", "quem pensa abstratamente?", ao elogio, enfim, "da filosofia".

Com efeito, é disso principalmente que se trata. Poderíamos, assim, sintetizar o propósito e algumas implicações da obra de Simone de Beauvoir - que, a meu ver, unem profunda e libertariamente dois termos historicamente mantidos em absoluto descompasso, a saber, mulher e filosofia - na seguinte exposição (e aqui faço minhas as palavras de Le Doeuff): "sobre a opressão das mulheres, não sabemos muito bem como ela surgiu, sabemos um pouco sobre como ela se mantém e como faz sofrer, em todo caso, ela está em vias de acabar ao menos um pouco, e é preciso que ela acabe por completo" (LE DOEUFF, 1989, p. 108). O futuro evocado por Simone de Beauvoir é da ordem do "é preciso que isto seja reversível" e não do "isto é reiterável": inclusive no mundo do conhecimento e da filosofia.

\section{Referências}

BEAUVOIR, Simone de. O Segundo Sexo, v. 2. Rio de Janeiro: Nova Fronteira, 2016.

BEAUVOIR, Simone de. Pour une morale de l'ambiguïté. Paris: Gallimard, 1947.

BEAUVOIR, Simone de. A força da idade. Rio de Janeiro: Nova Fronteira, 2009.

LE DOEUFF, Michèle. L'Imaginaneire philosophique. Paris: Payot, 1980.

LE DOEUFF, Michèle. L'Étude et le rouet - Des femmes, de la philosophie, etc. Paris: Édition du Seuil, 1989.

SARTRE, Jean-Paul. O ser e o nada. Petrópolis: Vozes, 1997.

Izilda Cristina Johanson (i.johanson@unifesp.br) é doutora em Filosofia pela Universidade de São Paulo e professora de Filosofia Contemporânea no Departamento e no Programa de PósGraduação em Filosofia da Universidade Federal de São Paulo. É membro dos grupos de trabalhos de Filosofia Francesa Contemporânea e de Filosofia e Gênero da Associação Nacional de PósGraduação em Filosofia, com estudos publicados nessas duas respectivas áreas. É autora dos livros Arte e intuição: a questão estética em Bergson (Humanitas, 2005) e Bergson - Pensamento e Invenção (FapUnifesp, 2014).

\section{COMO CITAR ESSE ARTIGO DE ACORDO COM AS NORMAS DA REVISTA}

JOHANSON, Izilda. "De objeto a sujeito: uma contribuição feminista à história e à filosofia". Revista Estudos Feministas, Florianópolis, v. 28, n. 2, e59273, 2020.

CONTRIBUIÇÃO DE AUTORIA

Autora que concebeu o artigo em todas as suas etapas e processos.

FINANCIAMENTO

Não se aplica

CONSENTIMENTO DE USO DE IMAGEM

Não se aplica

abolicionista e feminista branca Frances Gage e publicada em 1863. Esta é a versão traduzida aqui a partir de diversas fontes on-line - https://www.geledes.org.br/e-nao-sou-uma-mulher-sojourner-truth). 
APROVAÇÃO DE COMITÊ DE ÉTICA EM PESQUISA

Não se aplica

CONFLITO DE INTERESSES

Não se aplica

LICENÇA DE USO

Este artigo está licenciado sob a Licença Creative Commons CC-BY Internacional. Com essa licença você pode compartilhar, adaptar, criar para qualquer fim, desde que atribua a autoria da obra.

HISTÓRICO

Recebido em 19/09/2018

Reapresentado em 13/08/2019

Aprovado em 30/09/2019 